\title{
Prophylactic Antibiotic Treatment during Hysteroscopy: A Systematic Review
}

\author{
Jannie Wijma*, Paul J. Q. van der Linden \\ Deventer Ziekenhuis, Deventer, The Netherlands \\ Email: ${ }^{\text {jannie.wijma@gmail.com }}$
}

Received 3 February 2015; accepted 9 March 2015; published 12 March 2015

Copyright (C) 2015 by authors and Scientific Research Publishing Inc.

This work is licensed under the Creative Commons Attribution International License (CC BY). http://creativecommons.org/licenses/by/4.0/

c) (i) Open Access

\section{Abstract}

Background: Overall, the use of antibiotics is increasing. We noticed different practices amongst different hospitals in their prophylactic use of antibiotics during operative hysteroscopy. This review investigates whether there is sufficient evidence to recommend antibiotic prophylaxis in operative hysteroscopy. Methods: We performed a systematic search in "Pubmed" using "hysteroscopy" and "antibiotic" and "prophylaxis" as search items. We found 16 hits of which 4 were suitable to include in our review. Findings: In an included Cochrane review no conclusion was drawn since no articles could be included. A prospective study by Nappi et al. [1] support the recommendation of the American College of Obstetricians and Gynaecologists not to prescribe routinely antibiotic prophylaxis in cases of hysteroscopic surgery. Bhattacharya et al. conducted a prospective study that was ended prematurely. They conclude that there is no convincing evidence that prophylactic antibiotics are of value in hysteroscopy. A review by Morrill et al. yielded no new data. Conclusion: We did not find a significant increase in clinical relevant infectious symptoms after hysteroscopy in women treated with or without antibiotic prophylaxis, although data are insufficient to draw a definite conclusion. Therefore, we suggest a prospective study is mandatory on this topic.

\section{Keywords}

Antibiotic, Prophylaxis, Operative, Hysteroscopy

\section{Introduction}

During the last decades, we have seen an increase in the use of prophylactic antibiotics in surgery to prevent postoperative infections [2]. Probably due to this increase there has also been an increase in antibiotic resistance

${ }^{*}$ Corresponding author. 
with diverse negative consequences [3]. Hence, the advantages of prophylactic administration of antibiotics during surgery can be questioned. Also, current medical practice is getting more and more expensive, amongst others, due to widespread use of antibiotic medication.

When comparing pre-operative procedures in different hospitals, one can see differences in treatment options and protocols. For instance, in some medical centres it is common practice to administer prophylactic antibiotics in patients who undergo an operative therapeutic hysteroscopy, while in others this is not common practice. According to the Dutch Society for Obstetrics and Gynaecology (NVOG) [4] there is insufficient conclusive evidence on antibiotic prophylaxis in operative hysteroscopy. However, there is a suggestion that antibiotic prophylaxis can lower bacteraemia [5]. It is recommended that, to administer antibiotic prophylaxis to patients undergoing operative hysteroscopy. In particular in women with child wish. However, this recommendation is based on consensus. This recommendation is in accordance with the Royal College of Obstetricians and Gynaecologists (RCOG) guidelines on this topic. On the other hand, the American College of Obstetricians and Gynaecologists (ACOG) recommends not administering antibiotic prophylaxis in hysteroscopic surgery for everyone, without limitations or exceptions [6]. This recommendation is based on limited or inconsistent scientific evidence.

In summary, it seems that there is an increase in the use of antibiotic prophylaxis in surgery in general, but this is not always based on robust evidence. In this review we investigate whether there is sufficient evidence to recommend antibiotic prophylaxis in operative hysteroscopy.

\section{Methods}

We started our review query in database "Pubmed". The search keys where "hysteroscopy" and "antibacterial agents" and "antibiotic prophylaxis" and "therapeutic". This search produced 7 hits. We screened the titles and abstracts and found one article that was a general review on antibiotic prophylaxis in gynaecologic surgeries [7], one had no abstract available [8], two where on diagnostic hysteroscopy [9] [10], one on antibiotic treatment in hysteroscopy not otherwise specified [1], one in Italian [11] and one on enterocolitis following hysteroscopy [12]. This search only resulted in 7 hits. Therefore, we broadened our search by using less search items in database "Pubmed": "hysteroscopy" and "antibiotic" and "prophylaxis". Now, we found 16 hits, of which we again screened the titles and abstracts. Of these 16 hits, one article concerned a Randomized Controlled Trial (RCT) on antibiotic administration during operative hysteroscopy [7] and one regarded a Cochrane review [13]. The other articles were excluded after reading the titles and abstracts while being either non relevant articles, had no abstract available or where articles in languages other than English, German and Dutch.

In total, 4 articles were included in this review, one Cochrane Review [13], one RCT [7], one prospective study [14], and one study on antibiotic prophylaxis in gynaecologic surgery in general [6]. From this article, we only used information regarding antibiotic prophylaxis in hysteroscopy.

\section{Findings}

In Table 1, the primary results of the selected trials are shown. Most remarkable is the conclusion of the Cochrane Review [13]. At the moment of their review there were no RCT's available that assessed the effects of prophylactic antibiotics after transcervical intrauterine procedures. Hence the authors have included no article in their review, since no article fulfilled their inclusion criteria. Therefore, no conclusions could be drawn with regard of the use of antibiotic prophylaxis.

The included RCT of Nappi et al. [1] describes a double-blind, randomized, placebo-controlled study in which the incidence of infectious complications and the protective effect of antibiotic prophylaxis during operative hysteroscopy in an office setting is assessed. In total, 1046 patients were enrolled, that was randomly assigned to either reference group (i.e. given 1 gram of cefazolin intramuscularly) and study group (i.e. given $10 \mathrm{~mL}$ of isotonic sodium chloride solution). They found that 12 patients developed infectious complications, of whom 7 belonged to the study, i.e. untreated, group, and 5 belonged to the reference, i.e. treated, group. This was not a significant difference. All patients with infectious complications were treated with the same antibiotics where-after all symptoms resolved. Also, there were no serious infections with adnexal involvement. In conclusion, this study supports the recommendation of the American College of Obstetricians and Gynaecologists (ACOG) not to prescribe routinely antibiotic prophylaxis in case of hysteroscopic surgeries.

Bhattacharya et al. [14] describe a study that was conducted to study the effect of prophylactic antibiotics on 
Table 1. Results of included articles in review.

\begin{tabular}{|c|c|c|c|c|}
\hline Included Article & Objective & Study Design & Data/Results & Conclusion \\
\hline $\begin{array}{l}\text { Thinkhamrop et al. } \\
\text { 2013 [13] } \\
\text { Cochrane Review }\end{array}$ & $\begin{array}{l}\text { Effectiveness and safety of } \\
\text { antibiotic prophylaxis compared to } \\
\text { placebo or no treatment in women } \\
\text { undergoing transcervical } \\
\text { intrauterine procedures }\end{array}$ & $\begin{array}{l}\text { Systematic search in } \\
\text { different medical } \\
\text { databases, a.o. Pubmed }\end{array}$ & $\begin{array}{l}\text { No RCT's available, so no } \\
\text { trials were included }\end{array}$ & $\begin{array}{l}\text { No conclusion can } \\
\text { be drawn }\end{array}$ \\
\hline 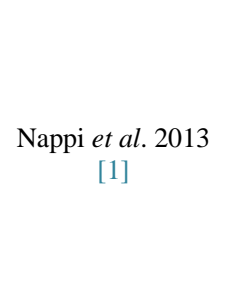 & $\begin{array}{l}\text { Double-blind, randomized, } \\
\text { placebo-controlled study to assess } \\
\text { incidence of infectious } \\
\text { complications and the protective } \\
\text { effect of antibiotic administration } \\
\text { during operative hysteroscopic } \\
\text { procedures in an office setting }\end{array}$ & $\begin{array}{l}\text { Reference group treated with } \\
\text { 1gram cefazoline i.m., study } \\
\text { group treated with placebo } 10 \\
\text { mL } \mathrm{NaCl} \text { solution. Primary } \\
\text { outcome: difference between } \\
\text { two groups in postoperative } \\
\text { infectious complications } \\
\text { within } 5 \text { days postoperative }\end{array}$ & $\begin{array}{l}1046 \text { women included; } 523 \\
\text { in study group, } 523 \text { in } \\
\text { reference group. } \\
\text { Postoperative infections: } \\
\text { 12/1046 (=1.15\%) women } \\
\text { had infectious } \\
\text { complications: } 7 \text { in } \\
\text { reference group, } 5 \text { in study } \\
\text { group (ns, p > } 0.05 \text { ) }\end{array}$ & $\begin{array}{l}\text { It is recommended } \\
\text { not to prescribe } \\
\text { routine antibiotic } \\
\text { administration in } \\
\text { the case of } \\
\text { hysteroscopic } \\
\text { surgery }\end{array}$ \\
\hline $\begin{array}{c}\text { Bhattacharya et al. } \\
1995[14]\end{array}$ & $\begin{array}{l}\text { Effect of prophylactic antibiotics } \\
\text { on the incidence of bacteraemia } \\
\text { following hysteroscopy }\end{array}$ & $\begin{array}{l}\text { Prospective randomised } \\
\text { study. Patients: } 106 \text { women } \\
\text { endometrial laser ablation or } \\
\text { transcervical resection of } \\
\text { endometrium intervention: } 55 \\
\text { women } 1200 \text { mg Augmentin } \\
\text { iv, } 61 \text { women no antibiotic } \\
\text { treatment. Blood culture after } \\
\text { procedure. }\end{array}$ & $\begin{array}{l}\text { Infection in untreated } \\
\text { group: } 16 \% \text { vs } 2 \% \text { in } \\
\text { antibiotic prophylaxis } \\
\text { group (significant } \\
\text { difference). Study } \\
\text { prematurely ended. } \\
\text { Eventually no difference in } \\
\text { clinically postoperative } \\
\text { infectious manifestations }\end{array}$ & $\begin{array}{l}\text { There is no } \\
\text { convincing } \\
\text { evidence that } \\
\text { antibiotics are of } \\
\text { value in this } \\
\text { clinical setting }\end{array}$ \\
\hline $\begin{array}{l}\text { Morrill et al. } 2013 \\
\text { [15] }\end{array}$ & $\begin{array}{l}\text { To critically review } \\
\text { gynaecology-specific data } \\
\text { regarding surgical antibiotic } \\
\text { prophylaxis in selected benign } \\
\text { gynaecologic surgeries }\end{array}$ & $\begin{array}{l}\text { Review including RCT’s on } \\
\text { benign gynaecological } \\
\text { surgeries other than } \\
\text { hysterectomy in which } \\
\text { antibiotic prophylaxis is } \\
\text { compared to placebo or no } \\
\text { antibiotic treatment }\end{array}$ & $\begin{array}{l}\text { Only one article included } \\
\text { on hysteroscopy: article by } \\
\text { Bhattacharya et al. } 1995\end{array}$ & $\begin{array}{l}\text { There is no } \\
\text { convincing } \\
\text { evidence that } \\
\text { antibiotics are of } \\
\text { value in this } \\
\text { clinical setting }\end{array}$ \\
\hline
\end{tabular}

the incidence of bacteraemia after hysteroscopic surgery. They conducted a prospective study including 116 patients. They underwent either an Endometrial Laser Ablation (ELA) or Transcervical Resection of Endometrium (TRCE). The patients were randomly assigned to a study group, that received $1.2 \mathrm{~g}$ of Augmentin i.v. prior to induction anaesthesia, while the other group did not receive any treatment (also excluding placebo). Blood cultures were obtained at the end of the surgical procedure. The study was discontinued after a short period since it showed that the incidence of bacteraemia in the non-antibiotic group (16\%) was significantly higher than that in the antibiotic group (2\%). However, these findings turned out to be of little clinical significance since no significant clinical difference between both groups could be found. Therefore, the authors concluded that there is no convincing evidence that prophylactic antibiotics are of value in hysteroscopy.

In the last included article by Morrill et al. [1] data regarding surgical antibiotic prophylaxis in several benign gynaecologic surgeries were critically reviewed. Our interest is on hysteroscopy. To answer this question, Morrill et al. [15] refer in their review to Bhattacharya et al. [14]. No other new articles on prophylactic antibiotics in hysteroscopy were included. Therefore, no extra data were included in our review. Before you begin to format your paper, first write and save the content as a separate text file. Keep your text and graphic files separate until after the text has been formatted and styled. Do not use hard tabs, and limit use of hard returns to only one return at the end of a paragraph. Do not add any kind of pagination anywhere in the paper. Do not number text heads - the template will do that for you.

\section{Conclusions}

In this systematic review we did not find a significant increase in clinical relevant infectious symptoms after hysteroscopy in women treated with or without antibiotic prophylaxis. Nevertheless, one can question whether this conclusion can be directly transferred to clinical practice.

The included trials are not all of good enough quality. For example, only one RCT was available to be in- 
cluded in the review. We expected to have more RCT's available. Moreover, not all included articles gave an answer to our question or were done in patients similar to our patient population. Therefore, we cannot extrapolate results of the included articles to our population and situation. In general, when executing the search for the current review, we found that little evidence is currently available. Lastly, the only article that completely intended to answer our research question ended the study prematurely. For these reasons, we cannot draw a final conclusion due to too little available evidence.

For us, the most important issue is whether currently we are not over treating patients when this is not strictly indicated. On the one hand one can argue that we can better be safe than sorry. In other words, it is better to treat a patient better than strictly necessary. On the other hand, when supporting this opinion it may result in unnecessary expensive health care and also stimulates antibiotic resistance.

Based on the available evidence, we conclude that there is not enough evidence to make a definitive conclusion. To find evidence for possibilities to achieve good clinical results with less treatment, less antibiotic resistance and less health care costs, we propose a clinical trial in which we compare the effect on clinical manifestations of infection by patients undergoing operative hysteroscopy in which the one half of the group is treated with antibiotic prophylaxis while the other half of the group is treated with nothing or a placebo. And for the future, perhaps such a protocol can be extended to other treatment options.

\section{References}

[1] Nappi, L., et al. (2013) Multicenter, Double-Blind, Randomized, Placebo-Controlled Study to Assess Whether Antibiotic Administration Should Be Recommended during Office Operative Hysteroscopy. Reprod Sci.

[2] National Institute for Public Health and the Environment, Ministry of Health, Welfare and Sport (2013) Consumption of Antimicrobial Agents and Antimicrobial Resistance among Medically Important Bacteria in the Netherlands.

[3] http://www.rivm.nl/dsresource?objectid=rivmp:216911\&type=org\&disposition=inline\&ns_nc=1

[4] NVOG Guideline (2006) Submukeuze myomen, diagnostiek en therapie.

[5] Hoogkamp-Korstanje, et al. (2012) Consumption of Antimicrobial Agents and Antimicrobial Resistance among Medically Important Bacteria in the Netherlands. Dutch Foundation of the Working Party on Antibiotic Policy, SWAB. National Institute for Public Health and the Environment.

[6] American College of Obstetricians and Gynecologists (ACOG) (2009) Antibiotic Prophylaxis for Gynecologic Procedures. American College of Obstetricians and Gynecologists, Washington DC.

[7] Scottish Intercollegiate Guidelines Network RCOP (1999) Hysteroscopic Surgery. SIGN Publication nr 37, Edinburgh.

[8] Damiani, G.R., et al. (2012) A Dangerous Trigger. The European Journal of Obstetrics \& Gynecology and Reproductive Biology.

[9] Gregoriou, O., et al. (2012) Antibiotic Prophylaxis in Diagnostic Hysteroscopy: Is It Necessary or Not? The European Journal of Obstetrics \& Gynecology and Reproductive Biology.

[10] Kasius, J.C., et al. (2011) Antibiotic Prophylaxis for Hysteroscopy Evaluation of the Uterine Cavity. Fertility and Sterility.

[11] Marchino, G.L., et al. (1994) Antibiotic Prophylaxis with Cefotaxime in Gynecological Endoscopy. Minerva Ginecologica.

[12] Turner, R.J. (1994) Pseudomembranous Enterocolitis after Gynecologic Endoscopy. Journal of the American Association of Gynecologic Laparoscopists.

[13] Thinkhamrop, J., Laopaiboon, M. and Lumbiganon, P. (2013) Prophylactic Antibiotics for Transcervical Intrauterine Procedures. Cochrane Database of Systematic Reviews.

[14] Bhattacharya, S., et al. (1995) A Prospective Randomised Study of the Effects of Prophylactic Antibiotics on the Incidence of Bacteraemia Following Hysteroscopic Surgery. The European Journal of Obstetrics \& Gynecology and Reproductive Biology.

[15] Morrill, M.Y., et al. (2013) Antibiotic Prophylaxis for Selected Gynecologic Surgeries. International Journal of Gynecology \& Obstetrics. 